\title{
The Urban Remains an Important Duty for the Elbasan Environment and Citizen
}

\author{
Phd Candidate. Albana Madhi \\ Lecturer, Faculty of Economy \\ "Aleksander Xhuvani" University, Elbasan, Albania \\ e-mail: albana.kacollja@uniel.edu.al / albana.madhi@yahoo.com \\ Prof.Ass.Dr.Gjergji Shqau \\ Lecturer, Faculty of Economy \\ "Aleksander Xhuvani" University, Elbasan, Albania \\ e-mail: gjergjishqau@yahoo.com
}

Msc.Aldi Lekaj

MP Management aldilekaj@gmail.com

Doi:10.5901/ajis.2014.v3n2p37

\section{Abstract}

Elbasan is considered one of the most important cities of Albania. From this point of view, the intervention in this unfavorable situation of urban wastes is a responsibility of every citizen. To create methodology of preparation of this article helped me a lot the utilization of the experience in the management area of the reconnoiter of urban remains by means of questionnaire, interviews and different information, photos and diagrams. The targets that the purposes of this article are connected with studying the concrete situation of urban wastes remains regarding the existing level of recycle rate, with managerial and runner skills in this operation, funds and projects (programs) that are educe to this part, and what is the perspective for the future. The augmentation of recycle rate is considered as an important and difficult part with a cost that after all about the studies exceed the main cost of public health that we pay today or will pay in the future. This article gives the possibility to study also the green situation, the development of tourism in Elbasan, and the perspectives for the augmentation of working places and the protection of different natural resources. The object is to make possible that the management and the economic concept may help the environment problems of the environment in Elbasan. Considering different profits coming by recycling the urban remains tried to find out more conclusions and give the corresponding recommendations in the end of the article.

Keywords: Recycle, Urban remains,Managerial concepts, Elbasan

\section{Introduction}

Urban, industrial and passive remains play an important role in the environment. Their latter-day impact from both, the studies and statistics of the environment office in the Commune and the Prefecture ensues that other environmental remains in this city may have past by. If until a day before Elbasan was classified as one of the most polluted areas from the different smog and fluids, today urban remains are classified as the most important ones in the recycle level in general or in the environment recycle structure. The recycle is the process of the absorption of the product in the end of its life cycle and the usage of one or the whole recycles to create another product. The recycle is a key component of the modern remains management. It is the third component of the "Reduce, Reuse, and Recycle" or of the recycle hierarchy. Elbasan city calculates on the average of about 28.000 tone urban remains in a year or around 77 tone urban remains in a day. Knowing that the number of the population in this civil centre (Elbasan) is around 125.000 people it results that the amount of the urban remains for a person is around 224 kilo in a year or 0,224 tone/people in a year.

From the accounts with the augmentation of the number of the population and also the businesses that operate in this city and which are considered as the most important factors in urban remains it results that their amount is predicted to increase around 30.000 tone/year. The equation taken from a study in another article(Gjergji Shqau 2008, pg.17) shows that this connection has the form:

$b 0=363 b 1=0,2$ and $b 2=1,8$ also $Y=b o+0,2 \times 1+1,8 \times 2$ 
$\mathrm{x} 1$ - is considered the development of the number of the population, whereas $\mathrm{x} 2$ - is considered the augmentation or the number of the businesses in the city.

Having this actual and predicted situation, the insertion in efficient of the urban remains has an important both instant as well as for the future. Currently we as a city have a field for the accumulation of the urban remains, meanwhile the conflicts and different disagreements, the non-fulfillments of some people's interests with and without power, etc, keep us away landfills which waits to be filled and give us more breathing. This means that the actual landfill which exists since the year 1985 has past all the allowed limited and now has become an "ecological bomb". A very important and economic project has not been financed since the year 1999 and nowadays the area planned as a landfill has become a residence area, by loosing totally its destination.

If the politic volition and the managerial skills of this field, the support from the government funds, as well as citizen's pressure will be in the required levels, nowadays we would have the chance to "celebrate" the 10 anniversary of the construction and the function of the new landfill and think about another new and modern landfill.

\section{Which is the cost that we are paying nowadays?}

As a result of non-fulfilled of this today we still have pollution from the remains burn, the drinking water toxicity as a result of the extension of the urban recycles near the Shkumbin River. This means that our health is in dangerous. Another question is: can this be avoided? The willingness and the skills to solve the problems are two important factors within local jurisdiction. From managerial point of view we can consider this as a leadership form which regarding the failing result has been with a lower willingness and relatively minimal capacity. The diagram below shows how many forms of leadership or management we can encounter in these situations:

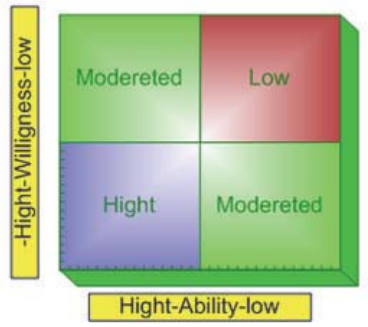

\section{Scheme I - Forms of leadership}

Our intention for the future is not to increase these problems. This means to increase the local administration willingness which deals with these problems and also to find convenient people for the work jobs in that way that those lead off the urban remains problems till the end. In the meeting of 15 January 2009 occurred in "Aleksander Xhuvani" University among the other things the Albanian premier Mr. Sali Berisha, pointed again the importance that takes the environment nowadays and the role of the Prefecture to realize a cleaner and healthier environment in Elbasan. The environment has many different problems but if these will be managed in an appropriate way, to aim more in a citizen and government for the recycles and projects maintenance or financial support for their recycle, the situation will be constantly improved. A mindful and educated consumer, being aware of the importance of the cleaning tax payment will be a very alleviating factor for the recycle process. On the other hand it is claimed that this tax to be managed better in the way to cover first not only $58 \%$ of the population according to the actual statistics but not even $80 \%$ according the predictions.

The accumulation of this tax is an organized and leadership duty, which can be solved in many ways. The little volition and leadership is a key factor in this course.

Why this tax from one side is not considered financially problematic but from the other side a very important one? Although according to the official information the unemployed number is around 16337 or $37,6 \%$ of the population, this number can not justify the cleaning tax that is 700 leke/year or (700/365=2 leke/day for a family with 4 persons). If this tax with an approximate account cover around 58\% then let's say that 1400 leke/year or 4 leke/day for a family will cover the entire city's population, this is unimaginable citizen cost. $5^{1}$

On the other hand the individual, familiar, social, citizen, national's profit, will be keeping clean the environment

\footnotetext{
1"Literature from municipal bulletin."
} 
and being healthy. This also means less medicaments that costs more than 4 leke/day for about 4 persons. The consumer education programs are spread in Europe and USA (and in the other developed countries). They have improved the consumer according to the different problems and also justify the rate costs with variant reversionary profits.

In USA according to the studies it is accounted that $75 \%$ of the remains can be recycled.

The recycle serves for two important goals:

1. It contains materials with aluminum paper quality, so they can be used again in other forms and can not be deposit or bury.

2. It keeps away the dangerous chemical materials such as mercury etc, dangerous toxic materials which pollute the ground and can be infiltrating by polluting in this way the drinking water as well.

This includes: battery, electronics, diesel, colors, and any product which has as a label "look out" or "Warning"

Why do I consider important the urban remains recycle?

Knowing its concept, through this process

First: we will reduce the landfill surface and then this will bring a cleaner environment. (Palmer, Joy. 1990.pg 72)

Second: it will take fewer rates in different costs sounds, because one part of the material is less consumed.

Third: less material usage means less utilization of the natural sources, so there are conserved different supplies.

Fourth: the fuel, combustibles, electrical energy's usage, etc, will be even lesser than the materials not to be profit from the recycle.

Fifth: flora and fauna, the water that we drink and the air that we inspire will be in toxic levels even lesser.

Sixthly: the account made have issued that the burn of around 10.000 tone remains creates a job while the deposit of the same amount in landfills creates 6 jobs, while the recycle of the same amount creates 36 jobs. ${ }^{2}$

\section{Do we have chances to manage the situation with the recycle programs and how can we compose these programs?}

There are some key elements for the beginning of each program about a business, school, organization's recycle or just at your home.

First: decide what to recycle? Evaluate the space you have in your shop, business, home, etc, and also how many materials and objects you have, what have the tendency to go for recycle according some rules such as: water bottle, tins, cartons, etc.

Second: find a person or a subject authorized for this problem. Control in your local recycle zone and commune or civil centre remains to find what kind of materials are accepted in your zone.

Third: select the kind of urban waste baskets which make possible the product recycle.

Fourth: control continually the waste basket to be in the required place and those that are appropriate, to respect the scantlings decided by the environmental specialists for their number (waste basket and the distance between them).

Fifth: deliver continually small paper leaf realization for the recycle importance and its profits, as well as the continually citizen's consultation or zone's people regarding to the costs that their buying has and the necessity to protect and maintain them.

Sixthly: family and relatives encouragement about recycle.

Seventh: recycle stimulation in your neighborhood or zone and let them know how to take part in this important process.

Eighth: try to involve as much as possible people in this program and process.

Ninth: give moral reward, thanksgiving, gratuity, being profit from the recycle of a person or a group of persons that are the most engaged in this process. (Adam S. Weinberg, David N. Pellow, Allan Schnaiberg. 222 pg)

Tenth: don't forget that the reward and the punishment congenial with one another which means that the reproaches and fines have to go along with those who destroy or harm the process rules.

It is understandable that in order to realize the programs first of all is claimed a mindful and educated society for the process importance, and second is the locative unit level and of the authorized subjects for the urban remains collection and their recycle.

These two important ways ask for time and work in order to be realized ascertaining in this way the actual situation where we are. The consumer is considered as an important part in the recycle process. All the products are composed 
having a consumer in mind. The consumers have the power to influence in the distinction with the buying they do which influence in the product success, apart from its respective. For those products that are considered less recycle in economic market conditions where the logo and article diversity is very large, a good culture can make them aware of the damage that this product may cause for the environment after the consume.

According this one it is the government duty and its rules and laws in order to create, to maintain and to reinforce the recycle process in all the possible links that it can be realized. For the moment according to the studies it results that in Elbasan city the recycle process is in a low percentage from around $58-60 \%$ of the urban remains chances and in around $70-75 \%$ that is the developed countries standard.

We can say that it doesn't exist an authentic recycle from the landfill because this recycle have to begin since the remains throw process since the furniture and machinery which helps in the product recycle. The techniques used in the recycle are numerous and different countries use different technology and combined ones to reach the given mission. Inside this mission are different objectives in different zones which can eliminate considerable parts of urban remains.

From the canvasses done for about 150 people it results some reasons for non-recycling.

Table I - Reasons for non recycling

\begin{tabular}{|cl|c|}
\hline 1. & have forgotten & $6 \%$ \\
\hline 2. & are not convinced & $16 \%$ \\
\hline 3. & don't know how & $4 \%$ \\
\hline 4. & have no recycle program or are poor & $16 \%$ \\
\hline 5. & other reasons & $17 \%$ \\
\hline 6. & lack of interest & $18 \%$ \\
\hline 7. & have no time & $14 \%$ \\
\hline 8. & lack of waste baskets & $3 \%$ \\
\hline 9. & have no recycle necessity & $6 \%$ \\
\hline
\end{tabular}

Graphically this canvass is presented as below:

- The cost-benefit analyses in connection with the recycle products.

From the analyses done to the recycle elements to urban remains results that they contribute in two directions:

First: reduce the spent energy

Second: reduce the environmental pollution.

From the accounts done we have the below results:

Table 2 - The effects of the recycle on the environment

\begin{tabular}{|l|c|c|}
\hline The materials & provident energy & air pollution \\
\hline Aluminum & $95 \%$ & $95 \%$ \\
\hline Cartons & $24 \%$ & --- \\
\hline Glass & $5-30 \%$ & $20 \%$ \\
\hline Paper & $40 \%$ & $73 \%$ \\
\hline Plastic & $70 \%$ & --- \\
\hline Iron & $60 \%$ & --- \\
\hline
\end{tabular}

Source: Recycling Program Design, Management, and Participation: A National Survey of Municipal Experience, in Public Administration Review by David H. Folz. Pg 10,22,33.

As it can been seen from the chart the evidences are clear. The aluminum is the most important component which saves more energy than the other ones. Then the plastic, iron, paper, are elements that have importance in energy saving which is $40 \%-70 \%$ and then cartons and glass are in lower segments in nearly $20 \%$ but have a calculated utility. Saving energy in an indirect way means, less carbon, fuel, oil and its components, less electricity. These natural resources are less consumed and our environment will be even more beneficial and stable. These last year fluctuations in the environment, temperature alterations, the augmentation of the ocean, river, seas, water level, different flooding, etc, damages that are caused also as a result of the natural balance break from products fabrication. From the studies done by the environment defense agency in USA it results that the recycle has saved to the America in the year 2005 about 49 million meter square tone carbon which had to be pulled out by the natural resources.

The cost-profit creation shows the advantages and disadvantages of each process. In this case the profits support the costs but let say that just from the first point of view. In the second aspect which is more directly according to the 
environmental protection, not all the composing elements of urban remains have an influence in the air pollution. According to the studies the recycle aluminum maintain air cleaning in about $95 \%$ more and then the paper and glass recycle reduce air pollution in about $73 \%$ and $20 \%$.

If these accounts we will add also remain effect in the environment then the profits will be even greater. A cleaner environment protect more the population health which means less stress, productive people and more active at work also less mistakes at work with more composition etc. A cleaner environment from the profits point of view means more chances for tourism development in the country zone, city, and region. The tourism growth means more incomes and then more development chances for these segments from the taxes that will be profit from these incomes. The other profits are seen even from the different aspects and point of view in the greenness, flora and fauna, which give a higher vitality to the life. Which are the costs that are meant to be paid from the native population?

First: financial costs are considered the bases ones. These costs as I said before are too small compared with the profits we will have from the environment cleaning.

Second: the costs which serve for the creation or development of businesses or company are those that will be engaged in products recycle.

The studies shows that although businesses and the government may invests in different forms and times, the people and environment profits go beyond them in any time

According to this problem a private business has build a recycle plant which eliminates a part of the city urban remains. The government engagements for the recycle zones in Metalurgji or Paper zone also show attention, although the application hasn't started yet.

Third: different investments that local and central jurisdiction do according to different equipments which help the recycle from the urban remains accumulation to the landfill or recycle zone. The maintenance of all this cleaning system, the consumer education programs, the susceptibility of the different society orders for this problem. All these and other things like these compose some of the recycle process costs. In general these costs can not go beyond the different profits that has and will have people especially society.

\section{Conclusions}

1. The urban remains recycle in Elbasan is a problem which asks for a solution.

2. There exist many projects, words or thoughts according to the recycle but till now nothing concrete is done by the government and local jurisdiction.

3. Only a small business is not enough to change the situation.

4. The heavy situation of the urban recycle is about two ten-day years old.

5. The local population is still unconscious for the importance of the urban remains preventable and the recycle importance.

6. This is also seen in the cleaning tax cash level.

7. The cleaning tariffs are unimportant compared with the population daylong costs.

8. According to the canvass the majority considers it as an interest lack and is not convinced in its correct usage.

9. The town hall use about $80 \%$ for the cleaning of the main part of the city.

10. Around $20 \%$ is financed by this town hall.

11. The citizen education about the importance of the urban remains cleaning is in low levels.

12. The politic and incapacities interrupt the urban remains management.

13. There exist management methods and techniques for making the situation favorable but the wish and the human capacity miss.

14. In schools and teaching programs these problems are rarely discussed.

15. In the capital city and other localities is undertaken a project about realization of thousand children in many central schools.

16. The project aims a better management of urban remains and selecting manners and a better deposit of them.

17. The accumulation places of urban remains are out of standards in people number.

18. Their quality at the same time is not in recycle favor.

19. Because of a poor organization the urban remains often go beyond the allowed capacities by ejaculating in this way in streets and pavements.

20. Those are not covered that cause different radiation.

21. There exist interest conflicts which interrupt population and people regarding the landfills and recycle places.

22. These conflicts increase and make deeper the pollution and the diseases. 
23. Many initiatives and projects have not been supported by the governments increasing in this way the folders in the files.

24. The control rates of the problems are lower than those of the gravity of the situation.

25. For the moment the costs have over passed the profits from the urban remains.

26. The most important costs are the health ones and those that hurt indirectly in the economy.

27. We don't know to utilize the profits we can have.

\section{Recommendations}

1. A quicker and bigger realization in population especially in schools.

2. Realization regarding the future beneficial and the correctness in cleaning wages.

3. The cleaning tax augmentation for a better cleaning and the extension of the profit zone from the cleaning.

4. More flexibility in cleaning tax direction regarding the family, incomes, and social class dimension.

5. We can possibly compensate a part of the regions with lower incomes for a cleaner city.

6. The schools have good contacts with the families in general.

7. A greater engagement of the government, local jurisdiction, etc, to find more projects in this line.

8. The immediately abandonment of financial interests and politics' malice, their elimination and the continuation to build the recycle places and harmless landfills.

9. Some thoughts have to exist in the fields, zones, to stimulate the recycle places by different industrialists.

10. Landfills should not been seen just as a deposit places but not to create further problems.

11. They have to be considered as a problem closure and not just its displacement.

12. Recycle places and landfills have to be seen even as jobs for a considerable segment of people.

13. In this way apart from the energy savings, fuel savings, etc, we also reduce the unemployed number.

14. We reduce the number of the sick people and develop a healthier generation.

15. If we recycle 1000 tone plastic we save around 3500 tone oil.

16. In order to produce 1 tone real and recycle paper we save around 4900 kilowatt electrical energy.

17. In this point of view we do ourselves and nature a favor by breathing more cleaning air and save around 15 trees.

18. If we will respect the recycle standards and other elements, the economic profits will be multidimensional.

19. The continued improvement of the equipments which realize the urban remains collection.

20. Better organization of work in this process, more intervention and willpower from the local units.

21. This will make the process easier and efficient.

22. A better work coordinator even with small units such as the communes, apart from the politic conviction with a common saying: "for a cleaner Elbasan"

\section{References}

In the responding of the questions support Ing.Vjollca Vyshka.

"Literature from municipal bulletin."

Request for investment funds for the landfill construction. -Ing .Vjollca Vyshka.

"Information for the high supervision group" Environment Office of Elbasan Prefecture)-compiler Ing.Beqir Kila

Different information to internet, magazine etc.

The consumer rights Consumer Behavior. GJERGJI SHQAU ELBASAN

Wkipedia-internet-Elbasani

Elbasani in a constant evolution.-Internet.

The Management of urban remains problems in Elbasan city -Gjergji Shqau December 2008

http://earth911.com/

Polpresert, Chongrak. Organic Waste Recycling. New York: John Wiley \& Sons, 1989.

Krull, Kathleen. It's My Earth, Too. New York: Delacorte Press, 1992.

Palmer, Joy. Recycling Plastic. New York: Franklin Watts, 1990.

The American Forest Institute. Project Learning Tree. Washington D.C., 1977.

Urban Recycling and the Search for Sustainable Community Development by Adam S. Weinberg, David N. Pellow, Allan Schnaiberg.

Recycling Program Design, Management, and Participation: A National Survey of Municipal Experience, in Public Administration Review by David H. Folz.

Municipal Recycling Performance: A Public Sector Environmental Success Story-Journal article- by David H. Folz; Public Administration Review, Vol. 59, 1999. 